\title{
Spectrum-Dependent Spiro-OMeTAD Oxidization Mechanism in Perovskite Solar Cells
}

\author{
Shen Wang, ${ }^{\dagger}$ Wen Yuan, ${ }^{\ddagger}$ and Ying Shirley Meng ${ }^{*}{ }^{\dagger}$ \\ ${ }^{\dagger}$ Department of NanoEngineering, University of California San Diego, 9500 Gilman Drive, La Jolla, California 92093, United States \\ ${ }^{\ddagger}$ Department of Chemistry, Michigan State University, East Lansing, Michigan 48824, United States
}

\section{Supporting Information}

ABSTRACT: We propose a spectrum-dependent mechanism for the oxidation of $2,2^{\prime}, 7,7^{\prime}$-tetrakis $(N, N$-di-p-methoxyphenylamine)-9, $9^{\prime}$-spirobifluorene (Spiro-OMeTAD) with bis(trifluoromethane)sulfonimide lithium salt (LiTFSI), which is commonly used in perovskite solar cells as the hole transport layer. The perovskite layer plays different roles in the SpiroOMeTAD oxidization for various spectral ranges. The effect of oxidized Spiro-OMeTAD on the solar cell performance was observed and characterized. With the initial long-wavelength illumination $(>450 \mathrm{~nm})$, the charge recombination at the

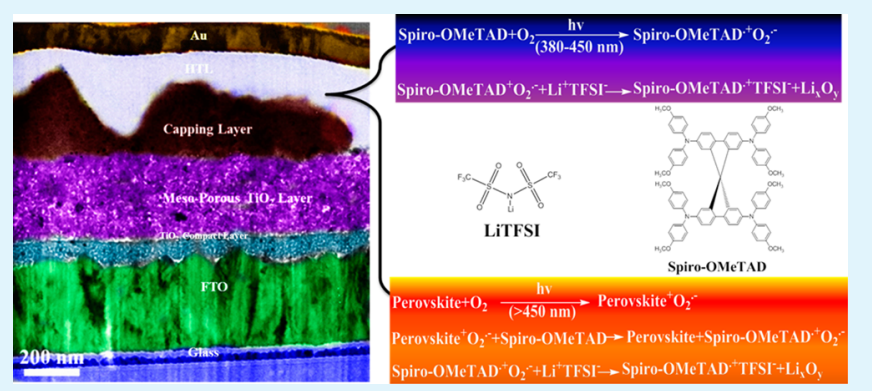
$\mathrm{TiO}_{2} /$ Spiro-OMeTAD interface was increased due to the higher amount of the oxidized Spiro-OMeTAD. On the other hand, the increased conductivity of the Spiro-OMeTAD layer and enhanced charge transfer at the $\mathrm{Au} /$ Spiro-OMeTAD interface facilitated the solar cell performance.

KEYWORDS: charge recombination, perovskite solar cells, solid state, p-doping, spectrum, impedance spectroscopy

\section{INTRODUCTION}

Hybrid organic-inorganic perovskite solar cells (PSCs) have gained increasing attention as intriguing candidates for nextgeneration photovoltaic devices since 2010. ${ }^{1}$ Recently, 20.1\% power conversion efficiency has been achieved through intramolecular exchange reaction. ${ }^{2}$ In addition to high efficiencies, PSCs are all-solid-state devices with low cost, a tunable band gap, and a scalable fabrication process, indicating its tremendous commercial prospects. ${ }^{3-8}$ The key components of PSCs (which contains meso-porous $\mathrm{TiO}_{2}$ ) include the blocking layer, metal oxide photoelectrode, perovskite layer, hole-transport material (HTM), and top electrode. ' When photons excite the electrons from the valence band (VB) to the conduction band $(\mathrm{CB})$ of the perovskite layer, excitons are generated. The excited electrons are injected into the $\mathrm{CB}$ of the metal oxide photoelectrode, and the holes are captured by the HTM in this charge separation process. The photogenerated electrons in the metal oxide are collected by a transparent conductive oxide and go to the external circuit. Electrons will recombine with holes at the top electrode to complete the circuit. ${ }^{10}$ The photovoltage of the PSC is equal to the difference between the quasi-Fermi level of the metal oxide photoanode and the redox potential of the HTM. ${ }^{11}$ The high hole collection efficiency at the perovskite/HTM interface is one of the key factors needed to achieve better efficiency in PSCs. ${ }^{12}$

One of the major developments for PSCs in recent years is the substitution of the liquid electrolyte to the solid-state HTM 2,2',7,7'-tetrakis ( N,N-di- $p$-methoxyphenylamine)-9,9' -spirobifluorene (Spiro-OMeTAD). This substitution dramatically improves the stability and the efficiency of PSCs. ${ }^{7,13}$ Unlike the liquid-based electrolyte, which can dissolve the perovskite layer, the small organic molecule Spiro-OMeTAD, shown in Figure 1a, is nonreactive to perovskite and is less volatile. The matched band gap with perovskite, amorphous nature, good conductivity with dopants, and high melting point for SpiroOMeTAD make it one of the most adaptable HTMs in PSCs. ${ }^{14-17}$ Recent research demonstrates that a > $400 \mathrm{~nm}$ thickness of Spiro-OMeTAD HTM layer can guarantee a higher open-circuit voltage and hinder the charge recombination at the $\mathrm{TiO}_{2} / \mathrm{HTM}$ interface. ${ }^{18}$

Surprisingly, the pristine uncharged form of Spiro-OMeTAD has a relatively low hole mobility and low conductivity before adding a $p$-dopant. ${ }^{19}$ Additives play a key role in improving the hole conductivity of the Spiro-OMeTAD layer and ultimately increase the efficiency of PSCs. Bis(trifluoromethane)sulfonimide lithium salt (LiTFSI) has been reported as a $p$ dopant to enhance the conductivity and hole mobility of the Spiro-OMeTAD. ${ }^{16,20-24}$ The function of LiTFSI in PSCs is quite similar to that in solid-state dye-sensitized solar cells (ssDSSCs). Some of the lithium ions can intercalate into $\mathrm{TiO}_{2}$ to downshift its conduction band, resulting in a higher photocurrent. $^{25-27}$ The rest of the lithium ions can react with oxygen and Spiro-OMeTAD to facilitate the generation of oxidized Spiro-OMeTAD, while the large anion $\mathrm{TFSI}^{-}$, as shown in Figure $1 b$, can stabilize the oxidized Spiro-OMeTAD as the counterion. $^{19-22,28,29}$

Received: August 19, 2015

Accepted: October 21, 2015

Published: October 21, 2015 
(a)

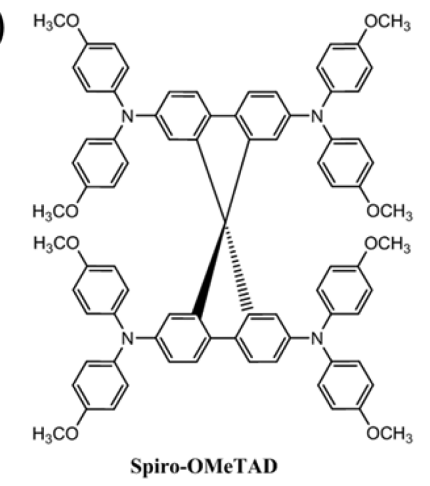

(b)<smiles>[CH]N(S(=O)(=O)C(F)(F)F)S(=O)(=O)C(F)(F)F</smiles>

LiTFSI

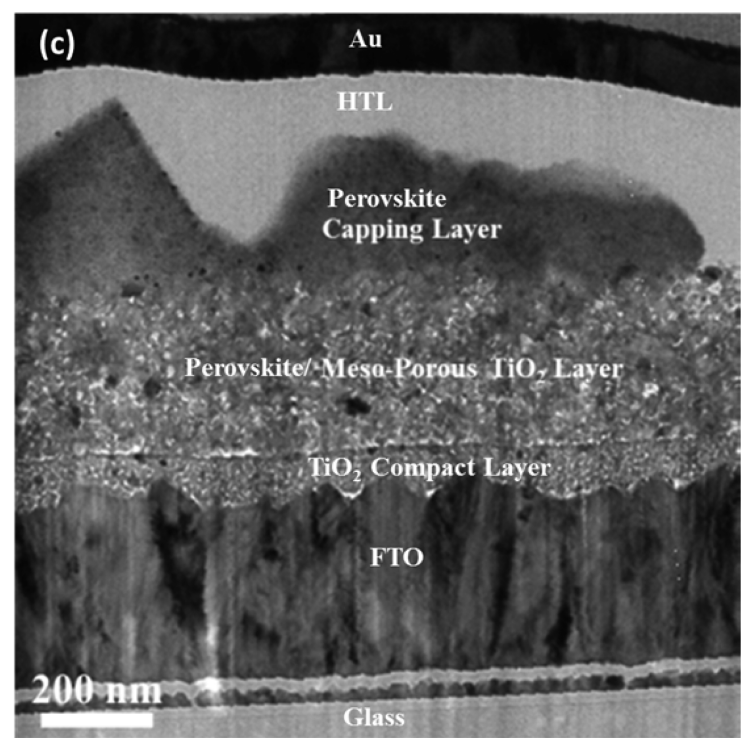

Figure 1. Molecular structures of (a) Spiro-OMeTAD and (b) LiTFSI; (c) cross-sectional BF-TEM image of full perovskite solar cell.

There are two different proposed mechanisms in the literature on the generation of oxidized Spiro-OMeTAD with the assistance of LiTFSI in DSSCs. Cappel et al. proposed a three-step mechanism where sensitizers are excited by photons and then the excited electrons are captured by oxygen. The oxidized Spiro-OMeTAD is created by regeneration of oxidized sensitizer. In the reactions, LiTFSI functions either as a catalyst or a stabilizer of the oxidized Spiro-OMeTAD. ${ }^{20}$ The mechanism is written as

$$
\begin{aligned}
& \text { Dye }+ \text { hv } \rightarrow \text { Dye* } \rightarrow \text { Dye }^{+}+\mathrm{e}^{-}\left(\mathrm{TiO}_{2}\right) \\
& \mathrm{e}^{-}\left(\mathrm{TiO}_{2}\right)+\mathrm{O}_{2} \rightarrow \mathrm{O}_{2} .^{-} \\
& \text {Dye }^{+}+\text {Spiro } \rightarrow \text { Dye }+ \text { Spiro }^{+}
\end{aligned}
$$

Later, Abate et al. proposed a two-step mechanism: first, equilibrium between Spiro-OMeTAD with oxygen and oxidized Spiro-OMeTAD (Spiro-OMeTAD $\cdot^{+} \mathrm{O}_{2} \cdot{ }^{-}$) exists; the equilibrium is moved forward by adding LiTFSI, because the superoxide radical $\mathrm{O}_{2}^{-}$reacts with $\mathrm{Li}^{+}$to form $\mathrm{Li}_{2} \mathrm{O}$ and $\mathrm{Li}_{2} \mathrm{O}_{2}$, and finally Spiro-OMeTAD ${ }^{+}{ }^{\mathrm{TFSI}^{-}}$is generated. ${ }^{19}$ The mechanism is written as

$$
\begin{aligned}
& \text { Spiro - OMeTAD }+\mathrm{O}_{2} \leftrightarrow \text { Spiro }-\mathrm{OMeTAD}^{+} \mathrm{O}_{2} \cdot{ }^{-} \\
& \text {Spiro - OMeTAD } \cdot{ }^{+} \mathrm{O}_{2} \cdot{ }^{-}+\mathrm{LiTFSI} \\
& \quad \rightarrow \text { Spiro - OMeTAD }{ }^{+} \mathrm{TFSI}^{-}+\mathrm{Li}_{x} \mathrm{O}_{y}
\end{aligned}
$$

The major difference between these two mechanisms is whether photons and sensitizers participate in the reactions. In the three-step mechanism, photons trigger the following reactions while the oxidized Spiro-OMeTAD is produced from the regeneration of sensitizers. In the two-step mechanism, neither photons nor sensitizers facilitated the formation of oxidized Spiro-OMeTAD. Moreover, initial illuminating treatment, which means to illuminate a solar cell for a while before testing its efficiency, also plays a key role on enhancing solar cell performance. It can be attributed to the $\mathrm{Li}^{+}$ migration and Spiro-OMeTAD oxidization, ${ }^{22}$ which supports the photons participating in the generation of the oxidized Spiro-OMeTAD.

Due to the similar device structure between DSSC and PSCs, the above mechanisms can be adapted to PSCs. Only a few studies have focused on the function of LiTFSI in the PSCs until now. Exploring the relations between these mechanisms and PSCs can help us understand the function of photons, LiTFSI, and perovskite on the formation of oxidized SpiroOMeTAD. It would allow us to find rational ways to further improve the efficiency of PSCs.

Herein, we report a systematic study of the origination of oxidized Spiro-OMeTAD in PSCs. With the combination of UV-vis, a solar simulator equipped with long-pass filters, fourpoint probe conductivity measurement, and electrochemical impedance spectroscopy, a spectrum-dependent mechanism is proposed based on the wide absorption range of perovskite. This mechanism that reconciles the difference in previously proposed mechanisms is applicable for various visible spectrum ranges to increase the amount of oxidized Spiro-OMeTAD and, finally, improve the efficiency of PSCs.

\section{EXPERIMENTAL METHODS}

2.1. Reagents and Materials. All materials, unless stated otherwise, were purchased from Sigma-Aldrich and used as received. Spiro-OMeTAD was purchased from Merck KGaA.

2.2. Synthesis of $\mathrm{CH}_{3} \mathrm{NH}_{3} \mathrm{I} . \mathrm{CH}_{3} \mathrm{NH}_{3} \mathrm{I}$ was synthesized according to the reported procedure. ${ }^{30}$ Fourteen milliliters $(14 \mathrm{~mL})$ of methylamine ( $40 \%$ in methanol, TCI) and $15 \mathrm{~mL}$ of hydroiodic acid were mixed at $0{ }^{\circ} \mathrm{C}$ and stirred for $1 \mathrm{~h}$. The solution was evaporated at $90^{\circ} \mathrm{C}$ for $1 \mathrm{~h}$ to obtain the deep-brown primary product. The product was redissolved in ethanol at $70{ }^{\circ} \mathrm{C}$, precipitated, and washed with diethyl ether several times until the product turned white. Finally, the product was dried at $60^{\circ} \mathrm{C}$ in a vacuum oven for $24 \mathrm{~h}$.

2.3. Device Fabrication. Perovskite solar cells were fabricated using the sequential deposition method. ${ }^{6}$ FTO glasses (Pilkington, TEC-15) were cleaned by an ultrasonic bath with detergent water, alkaline ethanol solution, and deionized water, sequentially; each cleaning step lasted for $15 \mathrm{~min}$. Then, the oxygen plasma cleaning step was applied for $10 \mathrm{~min}$ to remove the last traces of organic residues on the slides. 

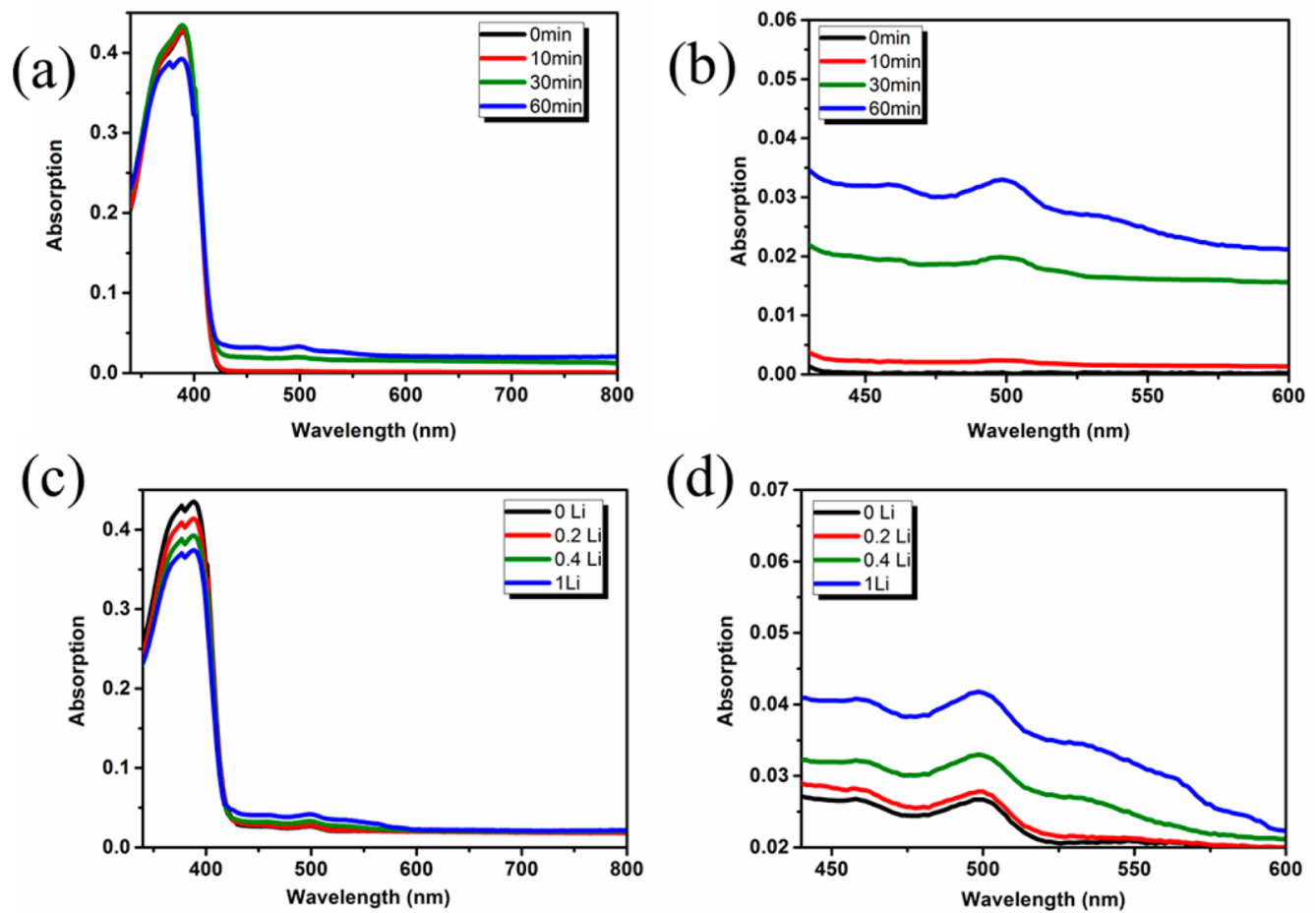

Figure 2. UV-vis absorption spectra of Spiro-OMeTAD in chlorobenzene at illumination times of 0, 10, 30, and 60 min with $0.4 \mathrm{LiTFSI} / \mathrm{Spiro}$ OMeTAD molar ratio at (a) full spectral range and (b) 450-600 nm range. Illumination for $1 \mathrm{~h}$ with LiTFSI/Spiro-OMeTAD molar ratios of 0, 0.2, 0.4 , and 1 at (c) full spectral range and (d) $450-600 \mathrm{~nm}$ range.

The $\mathrm{TiO}_{2}$ blocking layer (BL) was spin-coated on the FTO substrates at $800 \mathrm{rpm}$ for $1 \mathrm{~min}$ using $0.24 \mathrm{M}$ titanium isopropoxide in $5 \mathrm{~mL}$ of ethanol solution. The films were annealed at $500{ }^{\circ} \mathrm{C}$ for 30 min. After cooling to room temperature, the films were immersed in $0.03 \mathrm{M}$ aqueous $\mathrm{TiCl}_{4}$ solution at $70{ }^{\circ} \mathrm{C}$ for $40 \mathrm{~min}$ and then gradually heated at $500{ }^{\circ} \mathrm{C}$ for $40 \mathrm{~min}$ after washing with deionized water. Commercial $\mathrm{TiO}_{2}$ paste (Dyesol 18NRT, Dyesol) diluted in ethanol $(2: 7, \mathrm{w} / \mathrm{w})$ was spin-coated on the films at $5000 \mathrm{rpm}$ for $30 \mathrm{~s}$, and the film was annealed at $450{ }^{\circ} \mathrm{C}$ for $40 \mathrm{~min}$ to form the mesoporous $\mathrm{TiO}_{2}$ layer.

$\mathrm{PbI}_{2}$ solution $(1 \mathrm{M})$ was prepared by dissolving $462 \mathrm{mg}$ of $\mathrm{PbI}_{2}$ in 1

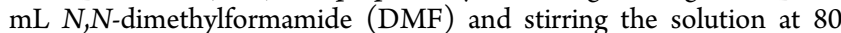
${ }^{\circ} \mathrm{C}$. The solution was spin coated on the films at $5000 \mathrm{rpm}$ for $90 \mathrm{~s}$. After spinning, the films were dried at $80^{\circ} \mathrm{C}$ for $30 \mathrm{~min}$ and dipped in 2 -propanol for $2 \mathrm{~s}$. Then the prewetted films were dipped in a solution of $\mathrm{CH}_{3} \mathrm{NH}_{3} \mathrm{I}$ in 2-propanol $\left(10 \mathrm{mg} \mathrm{mL}^{-1}\right)$ for $2 \mathrm{~min}$ and dried at 80 ${ }^{\circ} \mathrm{C}$ for $30 \mathrm{~min}$.

The $2,2^{\prime}, 7,7^{\prime}$-teterakis( $N, N$-di- $p$-methoxyphenylamine)-9,9-spirobifluorene (Spiro-OMeTAD) solution was prepared by $100 \mathrm{mg}$ of Spiro$\mathrm{OMeTAD}, 28.8 \mu \mathrm{L}$ 4-tert-butylpyridine (tBP) and $17.7 \mu \mathrm{L}$ lithium bis(trifluoromethanesulfonyl)imide (LiTFSI) solution $(520 \mathrm{mg}$ LiTFSI in $1 \mathrm{~mL}$ acetonitrile) in $1 \mathrm{~mL}$ of chlorobenzene. The solution was spin-coated on the $\mathrm{CH}_{3} \mathrm{NH}_{3} \mathrm{PbI}_{3}$ layers at $3000 \mathrm{rpm}$ for $1 \mathrm{~min}$. Finally, $80 \mathrm{~nm}$ of gold was e-beam evaporated on the Spiro-OMeTADcoated film.

The full perovskite solar cell structure is displayed in Figure 1c. The image was taken by the bright field transmission electron microscope (BF-TEM). The sample was thinned within $100 \mathrm{~nm}$ by focusing ion beam before taking the TEM image.

Devices for measuring the resistance of the hole conductor were fabricated as follows with the Spiro-OMeTAD solution identical to that used for the PSC fabrication, the solution spin-coated on glass substrates with/without perovskite $\mathrm{CH}_{3} \mathrm{NH}_{3} \mathrm{PbI}_{3}$ layer (the perovskite $\mathrm{CH}_{3} \mathrm{NH}_{3} \mathrm{PbI}_{3}$ layer was prepared as the same procedure as the PSC) at $3000 \mathrm{rpm}$ for $1 \mathrm{~min}$, the Spiro-OMeTAD coated films covered with a $100 \mu \mathrm{m}$ width spacer, and finally $80 \mathrm{~nm}$ of gold e-beam evaporated on the sample.
2.4. Device Characterization. Photocurrent density and voltage $(J-V)$ were measured with a solar simulator with a $150 \mathrm{~W}$ xenon lamp (Solar Light SL07265, equipped with an AM1.5G filter, calibrated with a standard Si solar cell to simulate AM1.5 illumination $(100 \mathrm{~mW}$ $\left.\mathrm{cm}^{-2}\right)$ ) and a Keithley 2400 source meter. Before the $J-V$ test, the solar simulator was marked with a $450 \mathrm{~nm}$ long-pass filter to illuminate the perovskite solar cell for $1 \mathrm{~h}$ and test its efficiency at $0 \mathrm{~min}, 10 \mathrm{~min}$, $30 \mathrm{~min}$, and $1 \mathrm{~h}$.

Electrochemical impedance spectra (EIS) were conducted using a Solartron 1287 electrochemical interface coupled with a Solartron $1455 \mathrm{~A}$ frequency response analyzer. A $10 \mathrm{mV}$ perturbation was applied, and the frequency was from $1 \mathrm{MHz}$ to $1 \mathrm{~Hz}$. The solar cell was illuminated by the solar simulator, which was integrated with the $450 \mathrm{~nm}$ long-pass filter for $1 \mathrm{~h}$, and the solar cell was tested by the EIS at $0 \mathrm{~min}, 10 \mathrm{~min}, 30 \mathrm{~min}$, and $1 \mathrm{~h}$, respectively. Final results for EIS were fit with Z-View. The equivalent circuit of EIS fitting is shown in Figure S1, and the fitting results are shown in Table S1, Supporting Information.

Resistance of the hole conductor was tested by four-point probe (Jandel Four-Point Probe with RM3000 Test Unit) measurement with the devices mentioned before in dark condition. The curves on the devices, which were created by the $100 \mu \mathrm{m}$ spacer, were set between the second and third probe during the test. Before testing, the devices were illuminated on solar simulator with full light, $380 \mathrm{~nm}$ long-pass filter and $450 \mathrm{~nm}$ long-pass filter for $0 \mathrm{~min}, 10 \mathrm{~min}, 20 \mathrm{~min}, 30 \mathrm{~min}, 40$ $\mathrm{min}$, and $1 \mathrm{~h}$, respectively.

2.5. UV-Vis Spectroscopy. UV-vis spectra were carried out in an absorption mode on a Lambda $1050 \mathrm{UV}-\mathrm{Vis}$ spectrometer. Measurements of the solutions were taken in a $10 \mathrm{~mm}$ quartz cuvette placed in a cuvette holder was integrated within the setup. The concentration of Spiro-OMeTAD for the UV-vis test was $8 \mu \mathrm{M}$ in chlorobenzene.

\section{RESULTS AND DISCUSSION}

The first aim of this study is to understand the function of photons on the generation of oxidized Spiro-OMeTAD. 


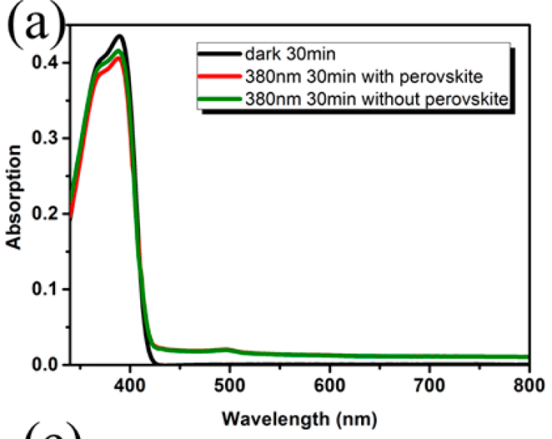

(c)

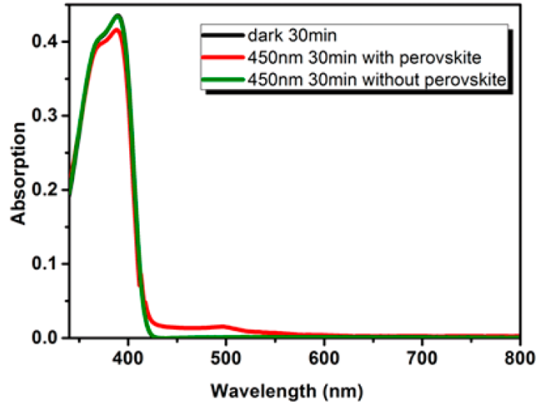

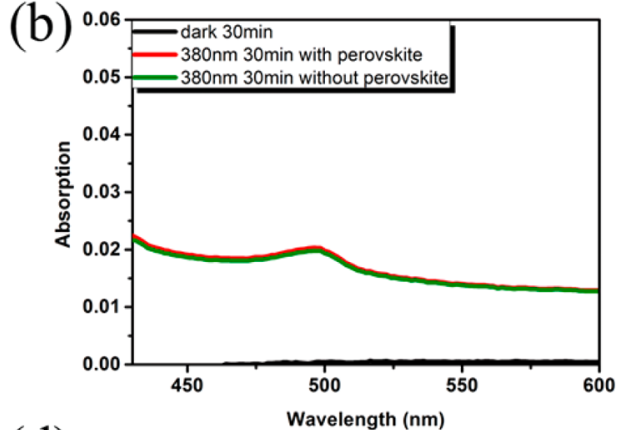

(d)

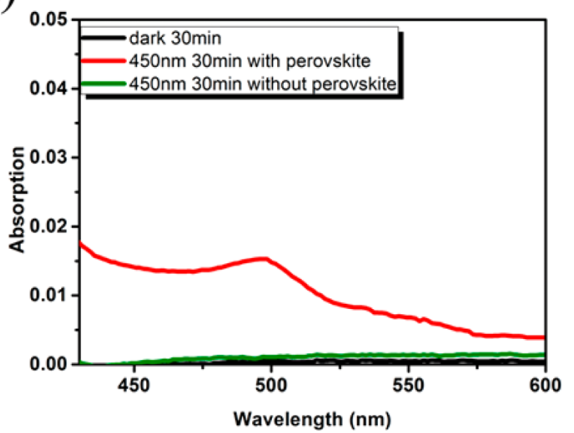

Figure 3. UV-vis absorption spectra of Spiro-OMeTAD/LiTFSI (0.4 LiTFSI/Spiro-OMeTAD molar ratio) in chlorobenzene with/without perovskite after $30 \mathrm{~min}$ illumination by AM1.5 $\left(100 \mathrm{~mW} \mathrm{~cm}^{-2}\right)$ solar simulator equipped with $380 \mathrm{~nm}$ long-pass filter at (a) full spectral range and (b) 450-600 $\mathrm{nm}$ range and $450 \mathrm{~nm}$ long-pass filter at (c) full spectral range and (d) 450-600 $\mathrm{nm}$ range.

According to the literature, the major UV-vis peak for SpiroOMeTAD is a sharp peak at $395 \mathrm{~nm}$, while oxidized SpiroOMeTAD is a sharp peak at $400 \mathrm{~nm}$ and an additional broad peak around $500 \mathrm{~nm} .{ }^{31}$ However, as the signal of SpiroOMeTAD around $395 \mathrm{~nm}$ often shields the oxidized SpiroOMeTAD $400 \mathrm{~nm}$ peak, the broad peak around $500 \mathrm{~nm}$ is usually considered as the indicator for the generation of oxidized Spiro-OMeTAD. ${ }^{19,28}$

Figure $2 \mathrm{a}, \mathrm{b}$ shows the influence of illumination time on Spiro-OMeTAD with LiTFSI in ambient condition at AM1.5 illumination $\left(100 \mathrm{~mW} \mathrm{~cm}^{-2}\right)$. The increasing absorption from 600 to $800 \mathrm{~nm}$ also implies the generation of oxidized SpiroOMeTAD as well, for the broad peak can extend to $800 \mathrm{~nm} .^{28}$ This illumination time-dependent signal illustrates that photons are participating in the generation of the oxidized SpiroOMeTAD in ambient condition.

Figure $2 \mathrm{c}, \mathrm{d}$ shows the effect of the LiTFSI concentration on the generation of oxidized Spiro-OMeTAD with the same illumination time; the samples are exposed to AM1.5 illumination $\left(100 \mathrm{~mW} \mathrm{~cm}^{-2}\right)$ for $1 \mathrm{~h}$. According to Figure $2 \mathrm{~d}$, even without adding lithium salt, after $1 \mathrm{~h}$ of illumination the broad $500 \mathrm{~nm}$ peak appears which means that LiTFSI is unnecessary for the generation of oxidized Spiro-OMeTAD. With only $\mathrm{O}_{2}$ and light, Spiro-OMeTAD oxidation can occur. However, with an increasing amount of LiTFSI, the amount of oxidized Spiro-OMeTAD also increased. This phenomenon indicates that although LiTFSI does not function in the generation of oxidized Spiro-OMeTAD, it can facilitate the Spiro-OMeTAD oxidation reaction to move forward. Therefore, LiTFSI acts as a "secondary reactant" to move forward the primary Spiro-OMeTAD oxidation reaction.

We then investigated the effect of the incident light wavelength on the oxidation reaction. Two different types of long-pass filters are separately equipped to the solar simulator to detect whether the reactions are spectrum-dependent. The function of the long-pass filter is to control the spectral range. It only allows the photons which have longer wavelength to pass through and illuminate on sample. For instance, the $380 \mathrm{~nm}$ long-pass filter only allows the light with wavelength longer than $380 \mathrm{~nm}$ to pass.

The Spiro-OMeTAD samples, as previously tested, are kept in ambient dark conditions for $30 \mathrm{~min}$ as the reference sample. According to Figure 3, no peak appears around $500 \mathrm{~nm}$ after 30 min when the sample was kept in ambient dark conditions. This supports our conclusion that Spiro-OMeTAD oxidization is optically activated.

As mentioned previously, the major absorption peak for Spiro-OMeTAD in UV-vis spectrum is $395 \mathrm{~nm}$, so it is possible that lower-wavelength light can trigger the following Spiro-OMeTAD oxidization. In contrast, at wavelength longer than $450 \mathrm{~nm}$, no absorption peak appears. The photons in this range $(>450 \mathrm{~nm})$ may not be energetic enough to overcome the activation energy for the oxidization reaction. Meanwhile, perovskite has a wide absorption range; the absorption spectrum for $\mathrm{CH}_{3} \mathrm{NH}_{3} \mathrm{PbI}_{3}$ extends to $800 \mathrm{~nm}$ while $\mathrm{CH}_{3} \mathrm{NH}_{3} \mathrm{Sn}_{0.5} \mathrm{~Pb}_{0.5} \mathrm{I}_{3}$ extends up to $1050 \mathrm{~nm} .^{32}$ The wide absorption range indicates that in a long wavelength range $(>450 \mathrm{~nm})$, it is possible that Spiro-OMeTAD oxidization reaction can proceed with the assistance of perovskite. On the basis of these assumptions, we equipped the solar simulator with 380 and $450 \mathrm{~nm}$ long-pass filters to investigate the spectrum-dependent roles of perovskite in the Spiro-OMeTAD oxidization.

As shown in Figure 3a,b, when the wavelength is longer than $380 \mathrm{~nm}$, after $30 \mathrm{~min}$ of illumination treatment, the oxidized Spiro-OMeTAD peak will appear regardless of the presence of a perovskite layer. This shows that in this spectrum range, it is unnecessary for perovskite to participate in the Spiro- 

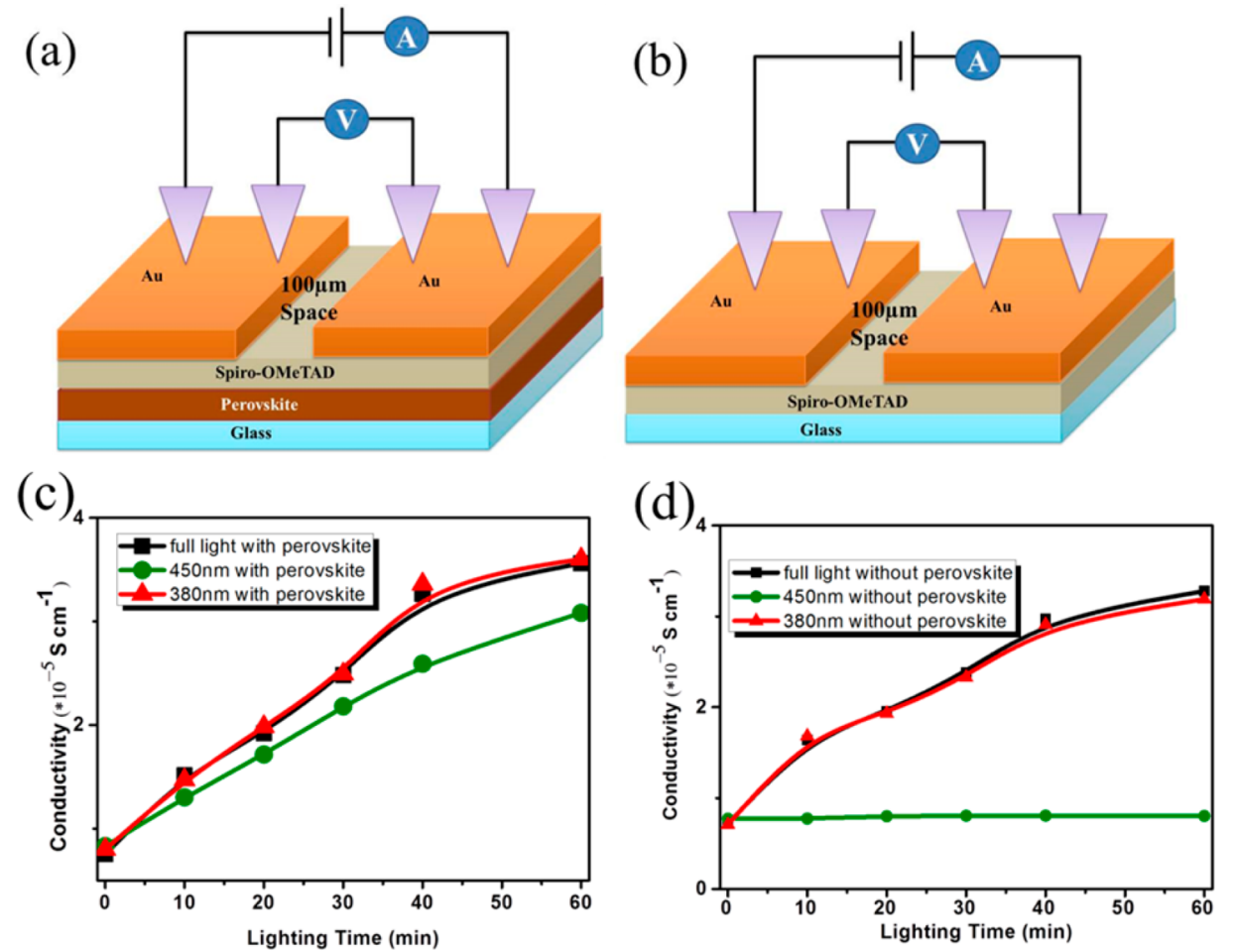

Figure 4. Effective conductivity of the hole transport layer (0.4 LiTFSI/Spiro-OMeTAD molar ratio) at various illumination times and spectral ranges measured by a four-point probe: (a) testing device structure with a perovskite layer, (b) testing device structure without a perovskite layer, (c) effective hole conductivity with perovskite layer, and (d) effective hole conductivity without perovskite layer.

OMeTAD oxidization. When using the $450 \mathrm{~nm}$ long-pass filter to illuminate the sample for $30 \mathrm{~min}$, as shown in Figure $3 \mathrm{c}, \mathrm{d}$, the oxidized Spiro-OMeTAD peak (around $500 \mathrm{~nm}$ ) only appears in the sample which has perovskite. This result proves that in long wavelength range, the perovskite sensitizer participates in oxidization. As a result, two mechanisms exist in the formation of the oxidized Spiro-OMeTAD: In the 380$450 \mathrm{~nm}$ spectral range, perovskite is unnecessary for SpiroOMeTAD oxidization, while in the $>450 \mathrm{~nm}$ spectral range, Spiro-OMeTAD needs the assistance of the perovskite to be oxidized.

We used liquid samples for UV-vis because UV-vis cannot rule out the spectral disturbance of the perovskite layer in the solid state. To further prove the spectrum-dependent hypothesis in solid state Spiro-OMeTAD, the conductivity of the hole transport layer was characterized by four-point probe measurement.

The device structure for the four-point probe measurements is shown in Figure 4a,b. A $100 \mu \mathrm{m}$ space is set between the second and third probes on each device to ensure the measurement of the hole transport layer conductivity. After the devices were illuminated by the solar simulator equipped with long-pass filters for a specific period of time $(0-60 \mathrm{~min})$, the conductivity was tested by four-point probe in dark condition in case less current flowed through the perovskite layer. If the Spiro-OMeTAD oxidization occurs, the total amount of ions in the hole transport increases, enhancing the conductivity of the devices.

As shown in Figure 4c, when the perovskite layer exists, the conductivity of all devices increased. The only difference in Figure $4 \mathrm{c}$ is that the device, which was illuminated with the 450 $\mathrm{nm}$ long-pass filter light, has a conductivity that improves slower than the other two. This can be attributed to the low illumination intensity compared to the full spectral illumination. It indicates that with the assistance of a perovskite layer, at a long wavelength range $(>450 \mathrm{~nm})$, Spiro-OMeTAD oxidization occurs. However, in the perovskite-free device, according to Figure $4 \mathrm{~d}$, even after $60 \mathrm{~min}$ of illumination, the $450 \mathrm{~nm}$ longpass illumination treatment does not change the device conductivity, which means little or no oxidized Spiro-OMeTAD is generated. The results of the conductivity test are in excellent agreement with the UV-vis characterization; oxidized Spiro$\mathrm{OMeTAD}$ is generated in the short wavelength range without perovskite, while in the long wavelength range, the generation of oxidized Spiro-OMeTAD is only possible with the assistance of the perovskite.

To understand the effect of long wavelength illumination on device performance, we fabricated perovskite solar cells and tested the efficiency after $>450 \mathrm{~nm}$ illumination initial treatment. As we stated before, in long-wavelength range, photons cannot trigger the Spiro-OMeTAD oxidization without perovskite. If perovskite did not participate in the reaction, no $J-V$ curve change should be observed as the exposure time increases. As shown in Figure 5 and Table 1, however, as the illumination time gets longer, the short circuit current density, fill factor, and cell efficiency improve within $30 \mathrm{~min}$ from 10 to $11.9 \%$. This can be attributed to the increasing amount of oxidized Spiro-OMeTAD. The oxidized Spiro-OMeTAD is generated after the long wavelength illumination treatment, and with the assistance of perovskite, more photoinduced electrons can be captured by oxidized Spiro-OMeTAD. As a result, the charge recombination of the solar cell rises at the Spiro$\mathrm{OMeTAD} / \mathrm{TiO}_{2}$ interface. At the same time, the oxidized Spiro-OMeTAD improves the conductivity and mobility of the hole transport layer. The balance of the negative effect (charge 


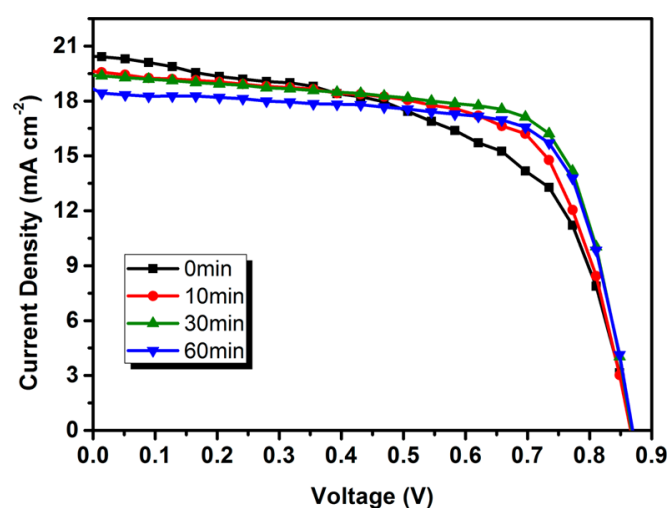

Figure 5. $J-V$ curves of the perovskite solar cells after $>450 \mathrm{~nm}$ illumination initial treatment.

Table 1. Cell Parameters of the Perovskite Solar Cells after an Initial Treatment of $>450 \mathrm{~nm}$ Illumination

\begin{tabular}{ccccc}
$\begin{array}{c}\text { illumination time } \\
(\mathrm{min})\end{array}$ & $\begin{array}{c}V_{\mathrm{OC}} \\
(\mathrm{V})\end{array}$ & $\begin{array}{c}J_{\mathrm{SC}} \\
\left(\mathrm{mA} / \mathrm{cm}^{2}\right)\end{array}$ & $\begin{array}{c}\text { fill } \\
\text { factor }\end{array}$ & $\begin{array}{c}\text { efficiency } \\
(\%)\end{array}$ \\
0 & 0.867 & 20.52 & 0.56 & 10.0 \\
10 & 0.870 & 19.68 & 0.66 & 11.3 \\
30 & 0.862 & 19.51 & 0.71 & 11.9 \\
60 & 0.860 & 18.72 & 0.71 & 11.5 \\
\hline
\end{tabular}

recombination) and positive effect (conductivity improvement) increases the solar cell efficiency in the first $30 \mathrm{~min}$.

After $30 \mathrm{~min}$ of long wavelength initial illumination treatment, the efficiency of the solar cell slightly decreases. This phenomenon might be more attributed to charge recombination caused by the higher concentration of oxidized Spiro-OMeTAD. Short-term stability issues such as migration/ accumulation of LiTFSI in the hole transport layer, ${ }^{21}$ moisture sensitivity, or degradation of the perovskite layer ${ }^{33}$ may also cause the slightly decrease of the efficiency. In general, the oxidized Spiro-OMeTAD will enhance the efficiency in a shortterm $(<30 \mathrm{~min})$, with a minor decrease in the efficiency afterward. As shown in Figure S2, Supporting Information, all the PSCs we fabricated display the same behavior after $>450$ nm illumination initial treatment. We also tested the PSCs after full light illumination initial treatment (Figure S3 and Table S2, Supporting Information). Quite similar behavior compared to the $>450 \mathrm{~nm}$ illumination initial treatment was observed through the solar cell parameters. The only difference is that the full light treatment cell reaches the maximum fill factor and efficiency within $10 \mathrm{~min}$ instead of $30 \mathrm{~min}$. This phenomena can be attributed to the oxidized Spiro-OMeTAD can generate faster with the full light illumination treatment than with the $>450 \mathrm{~nm}$ illumination treatment.

To further investigate the long wavelength light illumination influence on the PSC, electrochemical impedance spectroscopy (EIS) is applied to characterize the interfacial charge transfer and charge recombination of PSCs at various long wavelength illumination times.

The equivalent circuit of this model for PSC (Figure S1, Supporting Information) has been reported. ${ }^{34,35} R_{\mathrm{s}}$ represents the series resistance, while $R_{1}$ and $R_{2}$ correspond to the charge transfer resistance at the $\mathrm{Au} / \mathrm{Spiro}-\mathrm{OMeTAD}$ and Spiro$\mathrm{OMeTAD} / \mathrm{TiO}_{2}$ interfaces, respectively. According to the Nyquist plot in Figure $6 \mathrm{a}$ and the fitting results (Table S1, Supporting Information), in the first semicycle, which corresponds to $R_{1}, R_{1}$ will decrease with increasing illumination time. It is attributed to the increasing amount of the oxidized Spiro-OMeTAD that reduces the resistance at the $\mathrm{Au} / \mathrm{Spiro}-$ OMeTAD interface. By reducing $R_{1}$, we improved the cell performance of the oxidized Spiro-OMeTAD. Electrons are easier to transfer from the $\mathrm{Au}$ to the hole transport layer with more oxidized Spiro-OMeTAD.

On the other hand, as Figure $6 \mathrm{~b}$ shows, the second semicircle corresponding to $R_{2}$ increases with longer illumination time. It is attributed to the higher amount of oxidized Spiro-OMeTAD which leads to more charge recombination at the Spiro$\mathrm{OMeTAD} / \mathrm{TiO}_{2}$ interface. Some of the photogenerated electrons in the conduction band of $\mathrm{TiO}_{2}$ can be trapped by the increasing amount of the oxidized Spiro-OMeTAD. The increasing $R_{2}$ means that the oxidized Spiro-OMeTAD also negatively affects the cell performance. Because both the positive and negative effects coexist for the oxidized Spiro$\mathrm{OMeTAD}$ in the interfaces, the solar cell performance might increase in the first $30 \mathrm{~min}$ followed by a minor decrease.

According to EIS, after the long wavelength light treatment, the Spiro-OMeTAD oxidization reaction proceeds with the presence of perovskite. With the results shown, we propose a spectrum-dependent mechanism for the generation of oxidized Spiro-OMeTAD. Both the three-step mechanism ${ }^{20}$ and the two-step mechanism ${ }^{19}$ are applicable at different spectral ranges for the perovskite solar cells. In a short wavelength range (380$450 \mathrm{~nm}$ ), our proposed mechanism is similar to the two-step mechanism, and reactions can be written as
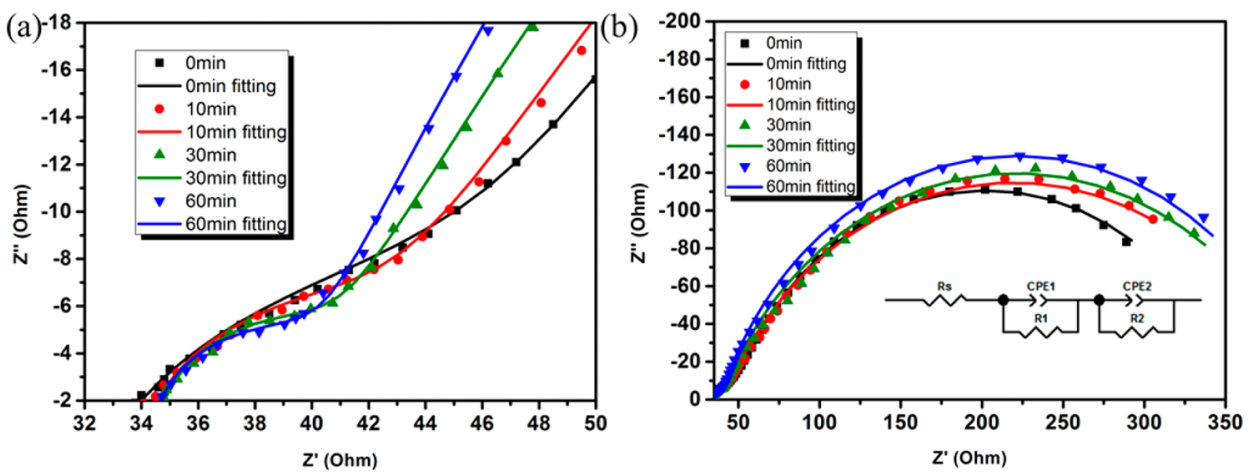

Figure 6. Nyquist plots of the perovskite solar cell with $>450 \mathrm{~nm}$ illumination from 0 to $60 \mathrm{~min}$ at a (a) high frequency range and (b) full frequency range; ( $b$, inset) equivalent circuit of the PSC. 


$$
\begin{aligned}
& \text { Spiro - OMeTAD }+\mathrm{O}_{2} \\
& \underset{(380-450 \mathrm{~nm})}{\longrightarrow} \text { Spiro }-\mathrm{OMeTAD}^{+} \mathrm{O}_{2} \cdot{ }^{-} \\
& \text {Spiro }-\mathrm{OMeTAD}^{+} \mathrm{O}_{2} \cdot{ }^{-}+\mathrm{Li}^{+} \mathrm{TFSI}^{-} \\
& \rightarrow \text { Spiro }-\mathrm{OMeTAD}^{+} \mathrm{TFSI}^{-}+\mathrm{Li}_{x} \mathrm{O}_{y}
\end{aligned}
$$

While in a long wavelength range $(>450 \mathrm{~nm})$, the three-step mechanism is more suitable with perovskite participating in the oxidization. The reaction is described as follows:

$$
\begin{aligned}
& \text { Perovskite }+\mathrm{O}_{2} \underset{(>450 \mathrm{~nm})}{\longrightarrow} \text { Perovskite }{ }^{+} \mathrm{O}_{2} \cdot{ }^{-} \\
& \text {Perovskite }{ }^{+} \mathrm{O}_{2} \cdot{ }^{-}+\text {Spiro }- \text { OMeTAD } \\
& \quad \rightarrow \text { Perovskite }+ \text { Spiro }-\mathrm{OMeTAD}^{+} \mathrm{O}_{2} \cdot{ }^{-} \\
& \text {Spiro - OMeTAD } \cdot{ }^{+} \mathrm{O}_{2} \cdot{ }^{-}+\mathrm{Li}^{+} \mathrm{TFSI}^{-} \\
& \quad \rightarrow \text { Spiro - OMeTAD } \cdot{ }^{+} \mathrm{TFSI}^{-}+\mathrm{Li}_{x} \mathrm{O}_{y}
\end{aligned}
$$

It is important to point out that we have not ruled out the possibility that both of the mechanisms coexist in a short wavelength range $(380-450 \mathrm{~nm})$, for perovskite is active in this range as well. Future work will focus on whether these mechanisms coexist in a short wavelength range, and the percentage of $\mathrm{Li}_{2} \mathrm{O}_{2}, \mathrm{Li}_{2} \mathrm{O}$, or both in these reactions will be characterized. Whether the presence of the lithium oxide species has any effect on degradation of PSC is of also our interest.

\section{CONCLUSION}

We demonstrated a spectrum-dependent mechanism for the generation of oxidized Spiro-OMeTAD in a perovskite solar cell and observed its influence on the solar cell performance. Photons participate in the reaction. In a short wavelength range (from 380 to $450 \mathrm{~nm}$ ), perovskite is unnecessary for the Spiro$\mathrm{OMeTAD}$ oxidization while in a long wavelength range $(>450$ $\mathrm{nm}$ ), the oxidization reaction can only proceed with the assistance of perovskite. The product, oxidized Spiro$\mathrm{OMeTAD}$, can improve the conductivity of the hole transport layer, and enhance the charge transfer at the $\mathrm{Au} / \mathrm{Spiro}-$ $\mathrm{OMeTAD}$ interface. However, it also increases charge recombination at the $\mathrm{TiO}_{2} /$ Spiro-OMeTAD interface. As a result, the initial illumination of a perovskite solar cell can enhance the efficiency; however, longer illumination times can reduce the efficiency of PSC. A better interfacial engineering method to hinder charge recombination at the $\mathrm{TiO}_{2} /$ SpiroOMeTAD interface while allowing increased generation of oxidized Spiro-OMeTAD would ensure better perovskite solar cell performance.

\section{ASSOCIATED CONTENT}

\section{S Supporting Information}

The Supporting Information is available free of charge on the ACS Publications website at DOI: 10.1021/acsami.5b07703.

Detailed information on EIS fitting (equivalent circuit and fitting results) and more $J-V$ curves and cell parameters. (PDF)

\section{AUTHOR INFORMATION}

\section{Corresponding Author}

*E-mail: shirleymeng@ucsd.edu.

\section{Author Contributions}

The manuscript was written through contributions of all authors. All authors have given approval to the final version of the manuscript.

\section{Notes}

The authors declare no competing financial interest.

\section{ACKNOWLEDGMENTS}

This work is supported by the seed funding from Sustainable Power and Energy Center (SPEC) under Frontier of Innovation Award by Vice Chancellor of Research at University of California San Diego. S.W. also gratefully acknowledges the Jacobs Graduate Fellowship by Jacobs School of Engineering at UC San Diego.

\section{REFERENCES}

(1) Kojima, A.; Teshima, K.; Shirai, Y.; Miyasaka, T. Organometal Halide Perovskites as Visible-Light Sensitizers for Photovoltaic Cells. J. Am. Chem. Soc. 2009, 131, 6050-6051.

(2) Yang, W. S.; Noh, J. H.; Jeon, N. J.; Kim, Y. C.; Ryu, S.; Seo, J.; Seok, S. I. High-Performance Photovoltaic Perovskite Layers Fabricated through Intramolecular Exchange. Science 2015, 348, 1234-1237.

(3) Liu, M.; Johnston, M. B.; Snaith, H. J. Efficient Planar Heterojunction Perovskite Solar Cells by Vapour Deposition. Nature 2013, 501, 395-398.

(4) Zhou, H. P.; Chen, Q.; Li, G.; Luo, S.; Song, T. B.; Duan, H. S.; Hong, Z. R.; You, J. B.; Liu, Y. S.; Yang, Y. Interface Engineering of Highly Efficient Perovskite Solar Cells. Science 2014, 345, 542-546.

(5) Chen, Q.; Zhou, H.; Hong, Z.; Luo, S.; Duan, H. S.; Wang, H. H.; Liu, Y. S.; Li, G.; Yang, Y. Planar Heterojunction Perovskite Solar Cells via Vapor-Assisted Solution Process. J. Am. Chem. Soc. 2014, 136, 622-625.

(6) Burschka, J.; Pellet, N.; Moon, S. J.; Humphry-Baker, R.; Gao, P.; Nazeeruddin, M. K.; Grätzel, M. Sequential Deposition as A Route to High-Performance Perovskite-Sensitized Solar Cells. Nature 2013, 499, 316-319.

(7) Lee, M. M.; Teuscher, J.; Miyasaka, T.; Murakami, T. N.; Snaith, H. J. Efficient Hybrid Solar Cells Based on Meso-Superstructured Organometal Halide Perovskites. Science 2012, 338, 643-647.

(8) Mei, A.; Li, X.; Liu, L.; Ku, Z.; Liu, T.; Rong, Y.; Xu, M.; Hu, M.; Chen, J. Z.; Yang, Y.; Grätzel, M.; Han, H. A Hole-Conductor-Free, Fully Printable Mesoscopic Perovskite Solar Cell with High Stability. Science 2014, 345, 295-298.

(9) Park, N. G. Perovskite Solar Cells: An Emerging Photovoltaic Technology. Mater. Today 2015, 18, 65-72.

(10) Jung, H. S.; Park, N. G. Perovskite Solar Cells: From Materials to Devices. Small 2015, 11, 10-25.

(11) Marchioro, A.; Teuscher, J.; Friedrich, D.; Kunst, M.; van De Krol, R.; Moehl, T.; Grätzel, M.; Moser, J. E. Unravelling the Mechanism of Photoinduced Charge transfer Processes in Lead Iodide Perovskite Solar Cells. Nat. Photonics 2014, 8, 250-255.

(12) Abate, A.; Planells, M.; Hollman, D. J.; Barthi, V.; Chand, S.; Snaith, H. J.; Robertson, N. Hole-Transport Materials with GreatlyDiffering Redox Potentials Give Efficient $\mathrm{TiO}_{2-}-\left[\mathrm{CH}_{3} \mathrm{NH}_{3}\right]\left[\mathrm{PbX}_{3}\right]$ Perovskite Solar Cells. Phys. Chem. Chem. Phys. 2015, 17, 2335-2338.

(13) Kim, H. S.; Lee, C. R.; Im, J. H.; Lee, K. B.; Moehl, T.; Marchioro, A.; Moon, S. J.; Humphry-Baker, R.; Yum, J. H.; Moser, J. E.; Grätzel, M.; Park, N. G. Lead Iodide Perovskite Sensitized AllSolid-State Submicron Thin Film Mesoscopic Solar Cell with Efficiency Exceeding 9\%. Sci. Rep. 2012, 2, 591.

(14) Kwon, Y. S.; Lim, J.; Song, I.; Song, I. Y.; Shin, W. S.; Moon, S. J.; Park, T. Chemical Compatibility Between a Hole Conductor and 
Organic Dye Enhances the Photovoltaic Performance of Solid-State Dye-Sensitized Solar Cells. J. Mater. Chem. 2012, 22, 8641-8648.

(15) Burschka, J.; Dualeh, A.; Kessler, F.; Baranoff, E.; Cevey-Ha, N. L.; Yi, C.; Nazeeruddin, M. K.; Grätzel, M. Tris(2-(1H-pyrazol-1yl)pyridine)cobalt(III) as p-Type Dopant for Organic Semiconductors and Its Application in Highly Efficient Solid-State Dye-Sensitized Solar Cells. J. Am. Chem. Soc. 2011, 133, 18042-18045.

(16) Yang, L.; Cappel, U. B.; Unger, E. L.; Karlsson, M.; Karlsson, K. M.; Gabrielsson, E.; Hagfeldt, A.; Johansson, E. M.; Sun, L.; Boschloo, G. Comparing Spiro-OMeTAD and P3HT Hole Conductors in Efficient Solid State Dye-Sensitized Solar Cells. Phys. Chem. Chem. Phys. 2012, 14, 779-789.

(17) Leijtens, T.; Ding, I. K.; Giovenzana, T.; Bloking, J. T.; McGehee, M. D.; Sellinger, A. Hole Transport Materials with Low Glass Transition Temperatures and High Solubility for Application in Solid-State Dye-Sensitized Solar Cells. ACS Nano 2012, 6, 14551462.

(18) Marinova, N.; Tress, W.; Humphry-Baker, R.; Dar, M. I.; Bojinov, V.; Zakeeruddin, S. M.; Nazeeruddin, M. K.; Grätzel, M. Light Harvesting and Charge Recombination in $\mathrm{CH}_{3} \mathrm{NH}_{3} \mathrm{PbI}_{3}$ Perovskite Solar Cells Studied by Hole Transport Layer Thickness Variation. ACS Nano 2015, 9, 4200-4209.

(19) Abate, A.; Leijtens, T.; Pathak, S.; Teuscher, J.; Avolio, R.; Errico, M. E.; Kirkpatrik, J.; Ball, J. M.; Docampo, P.; McPherson, I.; Snaith, H. J. Lithium Salts as "Redox Active" p-Type Dopants for Organic Semiconductors and Their Impact in Solid-State DyeSensitized Solar Cells. Phys. Chem. Chem. Phys. 2013, 15, 2572-2579.

(20) Cappel, U. B.; Daeneke, T.; Bach, U. Oxygen-Induced Doping of Spiro-MeOTAD in Solid-State Dye-Sensitized Solar Cells and Its Impact on Device Performance. Nano Lett. 2012, 12, 4925-4931.

(21) Hawash, Z.; Ono, L. K.; Raga, S. R.; Lee, M. V.; Qi, Y. AirExposure Induced Dopant Redistribution and Energy Level Shifts in Spin-Coated Spiro-MeOTAD Films. Chem. Mater. 2015, 27, 562-569. (22) Yang, L.; Xu, B.; Bi, D.; Tian, H.; Boschloo, G.; Sun, L.; Hagfeldt, A.; Johansson, E. M. Initial Light Soaking Treatment Enables Hole Transport Material to Outperform Spiro-OMeTAD in SolidState Dye-Sensitized Solar Cells. J. Am. Chem. Soc. 2013, 135, 73787385.

(23) Kazim, S.; Nazeeruddin, M. K.; Grätzel, M.; Ahmad, S. Perovskite as Light Harvester: A Game Changer in Photovoltaics. Angew. Chem., Int. Ed. 2014, 53, 2812-2824.

(24) Yuan, W.; Zhao, H.; Hu, H.; Wang, S.; Baker, G. L. Synthesis and Characterization of the Hole-Conducting Silica/Polymer Nanocomposites and Application in Solid-State Dye-Sensitized Solar Cell. ACS Appl. Mater. Interfaces 2013, 5, 4155-4161.

(25) Kopidakis, N.; Benkstein, K. D.; van de Lagemaat, J.; Frank, A. J. Transport-Limited Recombination of Photocarriers in Dye-Sensitized Nanocrystalline $\mathrm{TiO}_{2}$ Solar Cells. J. Phys. Chem. B 2003, 107, 1130711315.

(26) Yu, Q.; Wang, Y.; Yi, Z.; Zu, N.; Zhang, J.; Zhang, M.; Wang, P. High-Efficiency Dye-Sensitized Solar Cells: The Influence of Lithium Ions on Exciton Dissociation, Charge Recombination, and Surface States. ACS Nano 2010, 4, 6032-6038.

(27) Jennings, J. R.; Wang, Q. Influence of Lithium Ion Concentration on Electron Injection, Transport, and Recombination in Dye-Sensitized Solar Cells. J. Phys. Chem. C 2010, 114, 1715-1724.

(28) Nguyen, W. H.; Bailie, C. D.; Unger, E. L.; McGehee, M. D. Enhancing the Hole-Conductivity of Spiro-OMeTAD without Oxygen or Lithium Salts by Using Spiro(TFSI)(2) in Perovskite and DyeSensitized Solar Cells. J. Am. Chem. Soc. 2014, 136, 10996-11001.

(29) Tiwana, P.; Docampo, P.; Johnston, M. B.; Herz, L. M.; Snaith, H. J. The Origin of An Efficiency Improving "Light Soaking" Effect in SnO2 Based Solid-State Dye-Sensitized Solar Cells. Energy Environ. Sci. 2012, 5, 9566-9573.

(30) Im, J. H.; Lee, C. R.; Lee, J. W.; Park, S. W.; Park, N. G. $6.5 \%$ Efficient Perovskite Quantum-Dot-Sensitized Solar Cell. Nanoscale 2011, 3, 4088-4093.

(31) Fantacci, S.; De Angelis, F.; Nazeeruddin, M. K.; Grätzel, M. Electronic and Optical Properties of the Spiro-MeOTAD Hole
Conductor in Its Neutral and Oxidized Forms: A DFT/TDDFT Investigation. J. Phys. Chem. C 2011, 115, 23126-23133.

(32) Hao, F.; Stoumpos, C. C.; Chang, R. P.; Kanatzidis, M. G. Anomalous Band Gap Behavior in Mixed $\mathrm{Sn}$ and $\mathrm{Pb}$ Perovskites Enables Broadening of Absorption Spectrum in Solar Cells. J. Am. Chem. Soc. 2014, 136, 8094-8099.

(33) Guarnera, S.; Abate, A.; Zhang, W.; Foster, J. M.; Richardson, G.; Petrozza, A.; Snaith, H. J. Improving the Long-Term Stability of Perovskite Solar Cells with a Porous $\mathrm{Al}_{2} \mathrm{O}_{3}$ Buffer Layer. J. Phys. Chem. Lett. 2015, 6, 432-437.

(34) Xiao, Y.; Han, G.; Chang, Y.; Zhang, Y.; Li, Y.; Li, M. Investigation of Perovskite-Sensitized Nanoporous Titanium Dioxide Photoanodes with Different Thicknesses in Perovskite Solar Cells. J. Power Sources 2015, 286, 118-123.

(35) Kim, H. S.; Lee, J. W.; Yantara, N.; Boix, P. P.; Kulkarni, S. A.; Mhaisalkar, S.; Grätzel, M.; Park, N. G. High Efficiency Solid-State Sensitized Solar Cell-Based on Submicrometer Rutile $\mathrm{TiO}_{2}$ Nanorod and $\mathrm{CH}_{3} \mathrm{NH}_{3} \mathrm{PbI}_{3}$ Perovskite Sensitizer. Nano Lett. 2013, 13, 24122417. 